\title{
La construcción de la paz y el desarrollo de un nuevo modelo jurídico en Latinoamérica ${ }^{1}$
}

\author{
Manuel Bermúdez-Tapia ${ }^{2}$ \\ Universidad Privada San Juan Bautista \\ Paola Alexandra Sierra-Zamora ${ }^{3}$ \\ Escuela Militar de Cadetes "General José María Córdova” \\ Andrés Eduardo Fernández-Osorio ${ }^{4}$ \\ Escuela de Aviación del Ejército
}

\section{Introducción}

Debido a la generación de una serie de situaciones incidentales que van de lo particular a lo general, de lo nacional al contexto internacional (Adelman \& Paliwala, 1993), de lo especializado a lo genérico y del ámbito de la evaluación de una individualidad al análisis de una comunidad o grupo poblacional

1 Documento de investigación vinculado al proyecto Análisis de la Institucionalidad Democrática en el Perú, desarrollado en la Facultad de Derecho de la Universidad Privada San Juan Bautista.

2 Abogado (magna cum laude) de la Pontificia Universidad Católica del Perú. Magíster en Derecho y PhD en Derecho por la Pontificia Universidad Católica de Argentina. Profesor-investigador de la Universidad Privada San Juan Bautista y profesor de la Facultad de Derecho de la Universidad Nacional Mayor de San Marcos. Orcid: http://orcid.org/0000-0003-1576-9464 - Contacto: manuel.bermudez@upsjb. edu.pe

3 Abogada de la Universidad Católica de Colombia. Magíster en Derechos Humanos, Democracia y Justicia Internacional por la Universitat de València (España) y PhD (c) en Derechos Humanos, Democracia y Justicia Internacional de esta misma casa de estudios. Gestora de investigación del Departamento de Estrategia de la Escuela Superior de Guerra "General Rafael Reyes Prieto". Investigadora del Grupo de Investigación Persona, Instituciones y Exigencias de Justicia, de la Universidad Católica de Colombia, reconocido con código COL0120899, categoría A1 de Colciencias. Orcid: https:// orcid.org/0000-0002-3146-7418 - Contacto: paola.sierra@esdegue.edu.co

4 Teniente Coronel del Ejército Nacional de Colombia. PhD en Derecho y Ciencia Política, de la Universidad de Barcelona, España. Magíster en Economía, Estado y Sociedad: Política y Seguridad, University College London, Reino Unido. Magíster en Relaciones Internacionales, Higher School of Economics, Moscow, Federación de Rusia. Investigador del Grupo de Investigación en Aviación Militar de la Escuela de Aviación del Ejército. Orcid: https://orcid.org/0000-0003-0643-0258 - Contacto: andres. fernandez@buzonejercito.mil.co 
en específico, el derecho como institución que reproduce un valor sociocultural vinculante en lo subjetivo a una población se encuentra en un proceso de crisis (Miller, 2009), situación que repercute directamente en varias instituciones, como se desglosa a continuación:

a. En la legitimidad del Estado, pues se observa el quiebre del concepto de Estado-nación conforme a la tradición constitucional desarrollada desde la época moderna, concepto que no logra vincularse con la realidad de América Latina (Brachet-Márquez \& Uribe, 2016).

b. En la vigencia del poder del Estado, en el que hay presencia de actores ajenos a la esfera colectiva que institucionaliza la administración pública. Dichos actores, que han conquistado las esferas del poder público, son en realidad entes privados y de carácter supranacional, como las compañías transnacionales y el mercado, que imponen un esquema de uniformización superior a los intereses de los ámbitos locales nacionales.

c. En la prevalencia del concepto del bien común, que termina desarticulado cuando se observan situaciones de polarización social en los países de la región latinoamericana.

Por lo tanto, el modelo ético con el cual se ha conceptualizado a la mayoría de instituciones jurídicas en la región resulta insostenible no por una ausencia de conceptos aplicables, sino porque los factores políticos han incidido de modo directo en su propia ilegitimidad (Gross \& Ni, 2002). De acuerdo con esta situación, también se han visto afectados algunos principios y referencias de carácter jurídico, entre los cuales se destacan los siguientes:

a. La justicia, que no ha logrado atender a las víctimas, en particular, en casos de especialidad penal y en situaciones como la registrada en Colombia con la finalización del conflicto armado interno. Una situación muy diferente a la de los conflictos regionales registrados en Europa y Asia, conforme a los estudios de John-Hopkins (2017).

b. La funcionalidad de la democracia en América Latina, porque en los últimos años se ha podido evidenciar el desbalance entre la funcio- 
nalidad de las entidades del Estado y la cantidad de escándalos de corrupción masivos en los que estas se han visto involucradas, todo ello a consecuencia del empleo de los procedimientos de la administración pública en beneficio de intereses de particulares, lo que afecta severamente a la población y el erario nacional.

c. La institucionalidad de las entidades jurisdiccionales, especialmente, a raíz de una visión negativa de las políticas de Estado y las políticas públicas regionales, que no han logrado mejorar la prestación de sus servicios y el desempeño de sus funciones (impartir y administrar justicia) (Palacio \& Candioti, 2007). Ello ha provocado el quiebre en todos los niveles jurisdiccionales (ordinario y constitucional) en Perú, Colombia y Chile, países en los cuales se ha visto reflejada una mayor actividad de los órganos que componen el Sistema Interamericano de Protección de Derechos Humanos, con la Corte Interamericana de Derechos Humanos y la Comisión Interamericana de Derechos Humanos.

d. El ejercicio de tutela de derechos fundamentales se ha visto limitado y condicionado en función de una práctica generalizada en la región que no ha logrado superar el factor de impredictibilidad y de ejecución en un plazo razonable, para evaluar de forma efectiva un expediente judicial en determinado órgano jurisdiccional (Rey, 2011).

\section{Una crisis generalizada en la región latinoamericana}

Este proceso que ha venido desarrollándose en la región permite una evaluación teórica del derecho que se puede sistematizar en tres líneas específicas:

\section{a. El aspecto económico}

Las acciones políticas y económicas llevadas a cabo en la mayoría de los países de la región han dado como resultado economías nacionales incapaces de atender las necesidades de sus propias comunidades, con profundas brechas entre ricos y pobres (Knight $\&$ Drinot, 
2015). El descrédito y la disfuncionalidad de los modelos económicos impuestos de forma contraria a la realidad particular y especial de las comunidades nacionales ha provocado nuevos contextos de confrontación en la mayoría de los países en la región, por ejemplo: i. En el ámbito de la tutela de derechos vinculados a la protección de un ambiente o territorio, en situaciones en las que se planteaba la ejecución de actividades extractivas o de producción vinculada al ámbito de los hidrocarburos o el gas (BermúdezTapia, 2013).

ii. En el ámbito de la tutela de grupos vulnerables, como las comunidades indígenas, estas se han visto altamente desfavorecidas por las actividades productivas en minería, hidrocarburos o gas.

iii. En el ámbito de la atención de las necesidades de las poblaciones en situación de pobreza y extrema pobreza, estas no han sido cubiertas, sino que siguen en aumento, en una condición que muy pocos gobiernos han atendido en forma objetiva y de modo sostenible en el tiempo (Lloredo \& García, 2015).

iv. En atención a las desigualdades sociales, la diversidad de género, la accesibilidad laboral, la atención de servicios básicos y los servicios de justicia.

b. El valor instrumental del Estado en lo administrativo y lo constitucional Los Estados de la región latinoamericana han evidenciado una serie de situaciones que han provocado su falta de legitimidad social a un nivel que, hacia finales del 2019, se hizo fuertemente notorio en Ecuador, Perú, Chile, Argentina y Colombia. La crítica no se ha limitado a la evaluación de la gestión pública de los órganos del poder ejecutivo de cada país, sino que se ha extendido a todos los demás órganos que componen el Estado.

Esta crisis se ha masificado en Venezuela, Chile y Perú, con diferencias incidentales, con acciones de protesta ejecutadas por la población en cada uno de dichos países. Tales situaciones también se han visto reflejadas en la migración forzada de venezolanos, en el 
quiebre constitucional evidenciado por el cierre del Congreso de la República en el Perú y en la crisis social e institucional registrada en Chile (que llevó a una paralización del país que paradójicamente representaba el modelo económico y politico de éxito en la región).

c. La productividad jurisdiccional en lo referente a lo individual

Una de las principales evidencias de la crisis del derecho está expuesta en el ámbito evaluativo de la actividad jurisdiccional en la región latinoamericana. Factores como la impredictibilidad de las decisiones judiciales y el quiebre del plazo razonable en la evaluación de un proceso judicial —que provoca la desnaturalización del debido proceso y de la tutela judicial efectiva- se complementan con las esporádicas reformas institucionales en el sector, que culminan en la atención de las exigencias de la población.

\section{La justicia: elemento central en la disfuncionalidad del Estado}

Como se puede observar, el derecho se ha visto afectado tanto en su aspecto formal como en su aspecto conceptual, por las razones que se enuncian a continuación:

a. La ley no ha logrado estar a la altura de las exigencias sociales, debido a la poca productividad e innovación de los poderes legislativos en la región (Pásara, 2007). Las leyes especiales, funcionales o vinculantes de una política pública eficiente no son el patrón de referencia en la región y permiten observar características específicas como estas:

i. En el ámbito normativo penal, se ha enfatizado en las acciones punitivas que solo evalúan el incremento de las penas y no se atiende el problema criminológico que lo provoca.

ii. En el ámbito normativo civil, la atención de nuevas necesidades individuales, comunitarias y de exigencias colectivas (pretensiones difusas), si bien ha logrado algún reconocimiento en ciertos casos, resultan desvinculadas de otros ámbitos normativos. 
iii. En el ámbito constitucional, administrativo y ambiental, la legislación ha resultado ser disfuncional respecto de los problemas en evaluación, porque las condiciones en las cuales se debe atender una situación siguen siendo evaluadas desde una apreciación excluyente y teóricamente desfasada.

En este punto, obsérvese el nivel de productividad de la Corte Interamericana de Derechos Humanos, que prácticamente ha incidido en la evaluación crítica de la legislación nacional en varios países de la región.

b La labor académica que repercute en quebrantar lo dogmático ha estado limitada a una acción que ha complementado teorías e ideas ajenas al ámbito de las necesidades de la región. En este sentido, la inclusión de los derechos fundamentales en las constituciones nacionales ha respondido a la influencia de la Constitución española de 1978 y no a un fundamento autóctono.

Igual sentido está expresado en el ámbito de la mayoría de las especialidades jurídicas, lo cual denota una falta de articulación de teorías propias y autónomas frente a la doctrina comparada (Altava, 2003).

c. Una insuficiente actividad jurisdiccional, especialmente, en función a los dos puntos preliminares.

Como se puede apreciar, los Estados no están logrado legitimar su relación con la población, tal es la razón por la cual se ha dado el quiebre del contrato social que ha provocado el contexto de informalidad y generación de actividades paralelas al Estado por parte de la sociedad civil.

Los niveles de corrupción en la región latinoamericana evidencian lo acotado y explican el quiebre de la relación sinalagmática entre la población y el Estado (Bermúdez-Tapia, 2018), porque no se atiende a las condiciones particulares y especiales de cada parte, como tampoco se logra mejorar el carácter de interdependencia de ambas. Por el contrario, el ámbito democrático y de gobernabilidad son necesarios en una sociedad contemporánea, como lo exige un Estado de derecho. 


\section{La construcción de un Estado y una legislación a medida para la región latinoamericana}

Sobre la base del modelo clásico del Estado y de la ley, se debe reconocer el nivel de disfuncionalidad de ambos en el actual contexto regional. El modelo de Estado impuesto por España, Portugal, Francia e Inglaterra en América Latina resulta disfuncional, muy a pesar de que en estos países se registraron modelos monárquicos liberales, constitucionales y absolutistas que se impusieron en esta región durante su vinculación como colonias de aquellos (García, 2011).

Incluso el modelo no ha sido correctamente desarrollado en lo administrativo, puesto que, de la mayoría de los países independizados en el siglo XIX, solo unos pocos lograron un cierto nivel de funcionalidad cuando los grupos de poder pudieron mantener un clima de estabilidad política, económica y social en sus países (Mallorquín, 2018). Una referencia puntual es Argentina y Brasil. En el primero de ellos, el modelo de producción capitalista generó una condición de desarrollo sostenido que se ha visto limitado negativamente por las condiciones que su propio gobierno ha establecido en los últimos años. El modelo monárquico brasileño, en cambio, generó una condición de estabilidad política que se complementó en lo económico, social y cultural, lo que propició que en la actualidad Brasil superara a Portugal en los índices de evaluación industrial y de incidencia en la política y economía internacional.

En cambio, países como Perú, Colombia, Ecuador, Bolivia y Paraguay se han visto condicionados por sus grupos de liderazgo político y económico, situación que se ha ampliado en los últimos años en función de las acciones ejecutadas por sus propios gobiernos nacionales. Por su parte, Venezuela se diferencia del modelo evaluado por su condición económica basada en la producción y exportación de materia prima, factor afectado por las políticas asistencialistas que han provocado la severa crisis del país.

Chile, por otro lado, ha registrado el quiebre del modelo de exportación en lo económico y en lo político en la región, con lo cual ha provocado la imperiosa necesidad de atender el reclamo social con la cesión del Estado a ejecutar un proceso de reforma constitucional. 
Según esta breve revisión, es posible, entonces, afirmar que el modelo clásico del Estado europeo no ha logrado ser funcional en la región latinoamericana, porque hay elementos ajenos a la realidad en la cual se materializó su concepto, por ejemplo:

a. La delimitación geográfica cuenta, en la mayoría de los países, con presencia indígena, negra o mestiza en la región. En efecto, las realidades de las poblaciones indígenas en la Amazonía y en los Andes demuestran que las fronteras territoriales de los países son funcionales en cuanto al modo de vida tradicional de los pobladores preexistentes a los Estados, tras el proceso de colonización europea.

b. La amplitud de los valores socioculturales y lingüísticos en la región son diferentes a los de la realidad europea, y así deberían ser sus políticas de integración, diversidad cultural y transición. Pero hasta el momento no se ha logrado generar una asimilación cultural, por el contrario, se han limitado y condicionado a las poblaciones indígenas, las cuales se han vinculado a los ratios de pobreza y extrema pobreza en la región. Con suma dificultad se han protegido sus derechos, al alejarse de los ámbitos usuales en los cuales el Estado ejecuta sus acciones: zonas de difícil acceso a medios de comunicación.

c. La desvinculación de la población con la concepción de la soberanía popular que legitima al Estado y, por ende, a su administración pública. Una conclusión que se relaciona con el elevado nivel de ausencia del electorado en los comicios tanto en el ámbito regional como local en los países latinoamericanos.

Tales condiciones, en forma conjunta, quiebran el concepto de democracia, de gobernabilidad y de legitimidad del Estado, con lo cual se produce como consecuencia natural la crisis del derecho.

\section{La generación de un modelo autónomo, funcional y particular a raíz de la exigencia social}

De conformidad con lo visto hasta este punto es posible señalar algunos patrones generales en el ámbito regional latinoamericano: 
a. En Perú, Colombia, México, Bolivia y Ecuador surge la necesidad de articular modelos jurisdiccionales especiales, autónomos y funcionales con respecto a realidades particulares. En este sentido, para estos países se identifica:

i. Un sistema constitucional que reconoce el pluralismo jurídico.

ii Un sistema procesal que permite la viabilidad de nuevos modelos jurisdiccionales, como sucede en Colombia con la Jurisdicción Especial para la Paz a raíz del Acuerdo Final de Paz entre el Gobierno nacional y las FARC-EP.

iii. Un sistema normativo que permite evaluar y diferenciar capas de aplicabilidad de la ley a nivel individual, colectivo y de alcance difuso, según se hace patente en derechos de naturaleza personal, familiar, social, comunitaria y colectiva.

b. En México, Chile, Argentina, Colombia, Perú y Brasil surge la necesidad de articular los niveles de aplicabilidad de los programas macroeconómicos para que tengan incidencia en la microeconomía. Gracias a esto, los procesos de desarrollo incluirían a una mayor parte de la población, tanto en términos de productividad económica como de atención en servicios públicos básicos.

c En cada uno de los países de la región surge la necesidad de establecer programas y acciones que logren la integración nacional, tanto en lo que respecta a la infraestructura que permita la comunicación de toda su población a lo largo del territorio nacional, como respecto de la ampliación de las acciones estatales en zonas con escasa presencia (zonas alto-andinas, zonas amazónicas y zonas desérticas).

d. La atención de situaciones de emergencia social de condición extrema, como los conflictos internos evidenciados en Perú y Colombia.

e. La atención de problemas que superen el carácter nacional, en particular, cuando incidan negativamente en el ámbito interno, como sucede en México, Colombia, Perú y Chile en cuanto al problema del narcotráfico. 
Nótese que estos postulados no contradicen los alcances de la teoría tradicional, porque no se plantea la creación de un modelo excluyente, sino de un modelo que articule lo positivo de la teoría existente con una dosis de realidad expuesta a nivel cotidiano en la región latinoamericana.

\section{Referencias}

Adelman, S., \& Paliwala, A. (1993). Law and crisis in the Third World. School of Law University of Warwick.

Altava, M. (Coord.). (2003). Lecciones de derecho comparado. Universitat Jaume I.

Bermúdez-Tapia, M. (2013). El derecho a la consulta previa y su desarrollo en un estado unitario descentralizado. Diálogo con la Jurisprudencia, 168(18).

Bermúdez-Tapia, M. (2018). Legitimidad de la legislación en el Estado de derecho. En A. Martínez Lazcano, \& A. Islas Colín (Eds.), Derechos humanos: la transformación de la cultura jurídica. Ediciones Nueva Jurídica.

Brachet-Márquez, V., \& Uribe, M. (2016). Estado y sociedad en América Latina: acercamientos nacionales. El Colegio de México.

García, P. (2011). El Estado en América Latina: recursos e imaginarios, siglos XIX-XXI. Universitat de Barcelona.

Gross, O., \& Ni, F. (2002). Law in times of crisis: Emergency powers in theory and practice. Cambridge University Press.

John-Hopkins, M. (2017). The rule of law in crisis and conflict grey zones. Regulating the use of force in a global information environment. Routledge.

Knight, A., \& Drinot, P. (2015). La gran depresión en América Latina. Fondo de Cultura Económica.

Lloredo, L., \& García, L. (2014). Crisis económica. La globalización y su impacto en los Derechos Humanos. Editorial Universidad del Rosario.

Mallorquín, C. (2018). América Latina y su teoría. Ariadna Ediciones.

Miller, R. (2009) Law in crisis: The ecstatic subject of natural disaster. Standford University Press.

Palacio, J., \& Candioti, M. (2007). Justicia, politica y derechos en América Latina. Prometeo Libros.

Pásara, L. (2007). Los actos de la justicia latinoamericana. Universidad de Salamanca.

Rey, F. (2011). Los derechos en América Latina: tendencias judiciales recientes. Editorial Complutense. 